\title{
Simulation and Characteristics Analysis on Vibration and Sound Radiation Response for a Small Underwater Robot
}

\author{
Zhi Zhou \\ Yichang Testing Technology Research Institute, Yichang City 443003, Hubei Province, China
}

\begin{abstract}
An underwater robot is one of the important ocean equipment, and especially its stealth performance has influenced on the vitality in naval warfare. Structure radiation noise as the main source of underwater robot noise, so analysis on vibration and noise radiation is a topic of great concern. The way is used widely that based on fluid-solid coupling modal analysis combined with simulation on vibration and noise-radiation response in order to evaluate stealth performance of underwater structure. In the paper, firstly via finite element method and boundary element method, the modal frequencies and vibration modes of small underwater robot are calculated. Then the surface vibration displacements of underwater robot and the sound pressures of acoustic field under different frequency horizontal exciting force are obtained and analyzed. Lastly, through the analysis of the structural vibration and acoustic performance, the control strategies for structure bending vibration, acoustic radiation and structural acoustic design are proposed.
\end{abstract}

\section{Introduction}

With the development of application of underwater robot, it has been extended to underwater assault weapons step by step, so more and more high demands on stealth performance are necessary. However, the vibration and noise prediction and control technology not only affect greatly the stealth performance, but also influence the underwater robot vitality. Thus, the control technology of vibration and radiated noise for underwater robot is researched by navies in the world to decrease the likelihood of detection by sonar, and it is becoming an important evaluation index of underwater robot performance. The kinds of noises for underwater robots are divided into three categories [1-4]: structural noise, propeller noise and flow noise. The structural noise as above mentioned, is the underwater radiation noise by hull shell from the structure vibration caused by power equipment, and it is a major noise source. Especially at a slow speed and at a large depth, structure radiation noise is the main components of the total radiation noise level, and which accounts for about $70 \%$.

For most research on noise prediction method of underwater robot, the finite element method (FEM) and boundary element method (BEM) [5-7] are widely used. The finite element method is put forward in the 1950s, has been quickly applied to the analysis and calculation of acoustic radiation problems. The FEM is used as a solution method for inner sound field of limited region and different shape of the structure boundary. But like finite difference method, it needs to be subdivided in the entire analysis domain, and interpolated with variables, leading to too many calculating degrees of freedom. Meanwhile, for underwater robot, as a case of exterior acoustic radiation problem in infinite domain, the finite element method is difficult to determine the split edge resulting in large calculation errors. In order to solve the above problem, the boundary element method is presented in the 1960s, a kind of half-analytical and halfnumerical method which is solved by analytical equations within the domain and by the finite element method for the boundaries of the domain. So the numerical calculation degrees of freedom and too much original information are reduced, and it is suitable for solving infinite area of the sound field.

In the paper, the method combined the finite element method and boundary element method is used so as to analyze vibration and sound radiation response for a small underwater robot. Firstly, the structure vibration including flow-solid coupled modal is obtained by using the finite element method. Then the vibration response on the surface of the shell is set as a sound calculation input condition of the boundary of the analytical field. Lastly, the acoustical problem is solved by using the boundary element method for the infinite domain.

\section{The basic principle of FEM and BEM}

For underwater robot, the structure is dispersed into finite elements. Under the outer load to underwater robot, the overall dynamics control equation in air as followed:

$$
\left[M_{s}\right]\{\ddot{u}\}+\left[C_{s}\right]\{\dot{u}\}+\left[K_{s}\right]\{u\}=\left\{f_{s}\right\}
$$


Where, $\left[M_{\mathrm{s}}\right],\left[C_{\mathrm{s}}\right]$ and $\left[K_{\mathrm{s}}\right]$ are the mass, damping and stiffness matrix of the structure respectively. $\{\ddot{u}\}$, $\{\dot{u}\}$ and $\{u\}$ are the displacement, velocity and acceleration matrix of nodes of the finite element model. $\left\{f_{s}\right\}$ is the excitation force vector.

For the vibration of underwater robot in the sea, the interaction between seawater and outer surface of robot shell is produced physically, namely the fluid- structure coupling effect. The vibration of the shell produces sound pressure, and the pressure induces an opposite force that is exerted on the structural surface. The sound pressure is satisfied with the wave equation as below.

$$
\nabla^{2} p=\frac{1}{c^{2}} \frac{\partial^{2} p}{\partial t^{2}}
$$

Where, $c$ is the sound velocity. For the calculation process, the fluid domain is divided into numbers of finite elements. The sound pressures of field points, the displacements and corresponding order derivatives of time of mass points can be interpolated by values of the difference nodes. Then sound pressure mathematic variations are divided out. Considering damping effect, the finite element equation is deduced in the fluid acoustic field as followed.

$$
\left[M_{f}\right]\{\ddot{p}\}+\left[C_{f}\right]\{\dot{p}\}+\left[K_{f}\right]\{p\}+\rho_{f}[R]\{\ddot{u}\}=0
$$

Where, $\left[M_{f}\right],\left[C_{f}\right]$ and $\left[K_{f}\right]$ stand for fluid mass, damping and stiffness matrix respectively. $[R]$ represent the coupling mass matrix. The $\rho_{f}$ is the fluid density. $\{p\}$ is the node pressure matrix. With combining Eq.1 and Eq.3 simultaneous, the whole bending vibration controlling equation of underwater robot under the action from fluid-structure interaction can be deduced as below.

$$
\begin{aligned}
& \left\{\begin{array}{cc}
{\left[M_{s}\right]} & {[0]} \\
\rho_{f}[R] & {\left[M_{f}\right]}
\end{array}\right\}\left\{\begin{array}{l}
\{\ddot{u}\} \\
\{\ddot{p}\}
\end{array}\right\}+\left\{\begin{array}{cc}
{\left[C_{s}\right]} & {[0]} \\
{[0]} & {\left[C_{f}\right]}
\end{array}\right\}\left\{\begin{array}{l}
\{\dot{u}\} \\
\{\dot{p}\}
\end{array}\right\}+ \\
& \left\{\begin{array}{cc}
{\left[K_{s}\right]} & -[R]^{T} \\
{[0]} & {\left[K_{f}\right]}
\end{array}\right\}\left\{\begin{array}{l}
\{u\} \\
\{p\}
\end{array}\right\}=\left\{\begin{array}{l}
\left\{f_{s}\right\} \\
\{0\}
\end{array}\right\}
\end{aligned}
$$

The boundary element is a new numerical method for solving mathematical physics equation. This method is to change differential equations of the physics problem into a boundary integral equation. Then boundary of the region is divided into many finite elements, namely discrete boundary integral equation, so the equations only including the nodes' unknown variables on the boundary are obtained. In final, the numerical solution can be realized.

Under single frequency excitation force load, the Helmholtz integral solutions of acoustic wave equation [7] are calculated based on the equation:

$$
\begin{aligned}
& \rho\left(r_{p}\right)=\alpha\left(r_{p}\right) \iint_{S}\left[p\left(r_{p}\right) \frac{\partial G\left(r_{p}, r_{q}\right)}{\partial n}-\right. \\
& G\left(r_{p}, r_{q}\right) \frac{\partial p\left(r_{q}\right)}{\partial n} d S r_{q}
\end{aligned}
$$

Where $r_{p}$ is the location of observation point. $S$ is the surface of the sound source. $\alpha\left(r_{p}\right)$ is related to the region that contains the $r_{p}$ point, and it is also related to the case that if the surface $S$ is smooth and closed or not. $G\left(r_{p}, r_{q}\right)$ is Green function.

$$
G\left(r_{p}, r_{q}\right)=\frac{e^{-i k R\left(r_{p}, r_{q}\right)}}{4 \pi R\left(r_{p}, r_{q}\right)}
$$

Where $R\left(r_{p}, r_{q}\right)=\left|r_{p}-r_{q}\right|$.

\section{Simulation and characteristics analysis on vibration response for underwater robot}

The underwater robot researched in the paper, is a small robot, which can be used in underwater exploration, underwater investigation, obstacle avoidance and rescue mission. The outside view is illustrated in Fig.1.As only the radial excitation from the propeller is studied in this work, the vibration and radiated noise of the shell caused by axial vibrations of the propeller is not considered. What's more, to make the problem even simpler, the rudder and propeller are neglected in simulation. Its geometric parameters including shell and ribs are shown in Fig.2, Fig.3 and Tab.1. The material of underwater robot is aluminium alloy and its parameters: modulus of elasticity $E=82,000 \mathrm{MPa}$, Poisson's ratio $\mu=0.3$, density of solid $\rho_{s}=2,750 \mathrm{~kg} / \mathrm{m}^{3}$. The density of fluent $\rho_{f}=1,000$ $\mathrm{kg} / \mathrm{m}^{3}$, and sound velocity $c=1,500 \mathrm{~m} / \mathrm{s}$.

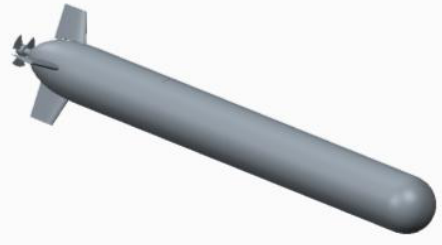

Figure 1. Outside view of underwater robot

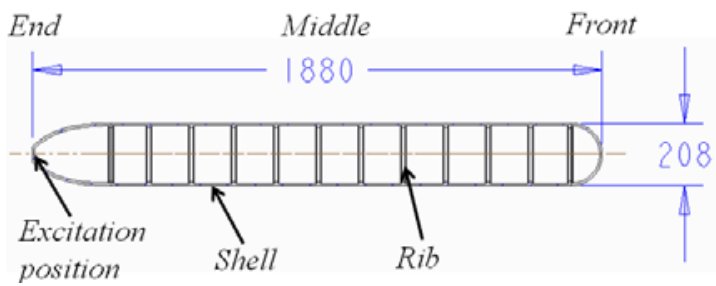

Figure 2. Profile section of underwater robot 


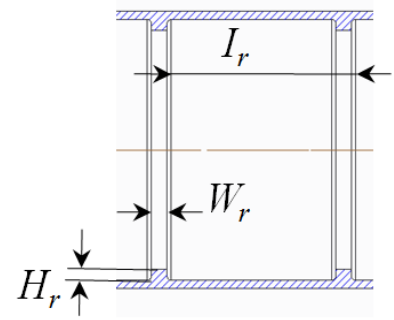

Figure 3. The geometry of ribs

Table 1. Geometric parameters of profile section

\begin{tabular}{|c|c|c|}
\hline \multicolumn{3}{|c|}{ Robot shell } \\
\hline $\begin{array}{c}\text { Outer } \\
\text { diameter/mm }\end{array}$ & Thickness/mm & Length/mm \\
\hline 208 & 6 & 1,880 \\
\hline \multicolumn{3}{|c|}{ Ribs } \\
\hline
\end{tabular}

\begin{tabular}{|c|c|c|}
\hline$H_{r} / \mathrm{mm}$ & $W_{r} / \mathrm{mm}$ & $I_{r} / \mathrm{mm}$ \\
\hline 8 & 12 & 140 \\
\hline
\end{tabular}

It is important to note that the underwater structure modal calculation method is different from the usual structural modal calculation method in the air, and it must be based on the fluid-structure coupling theory for underwater robots. Firstly the geometric model is simplified and meshed into finite element model. Then considered underwater fluid effect, the analysis model is established with a fluid-structure coupling surface. The constraints of the modal analysis are free for six degrees of freedoms. Through the modal analysis and calculation of fluid-solid coupling, the coupling modal frequency and air modal frequency results within frequency range $1 \mathrm{~Hz}-$ $1000 \mathrm{~Hz}$ as indicated in Tab.2.

Table 2. Modal results of underwater robots

\begin{tabular}{|c|c|c|c|c|c|}
\hline \multicolumn{3}{|c|}{ Air modal } & \multicolumn{2}{c|}{ Coupling modal } \\
\hline Order & Frequency/Hz & Modal behavior & Order & Frequency /Hz & Modal behavior \\
\hline 1 & 349.889 & 2-node bending /X & 1 & 160.684 & 2-node bending /X \\
\hline 2 & 353.724 & 2-node bending /Y & 2 & 160.69 & 2-node bending /Y \\
\hline 3 & 711.084 & 1-order radial collapse /X & 3 & 279.545 & 1-order radial collapse /X \\
\hline 4 & 714.442 & 1-order radial collapse /Y & 4 & 280.642 & 1-order radial collapse /Y \\
\hline 5 & 768.551 & 2-order radial collapse /X & 5 & 307.134 & 2-order radial collapse /X \\
\hline 6 & 771.863 & 2- order radial collapse /Y & 6 & 308.226 & 2- order radial collapse /Y \\
\hline 7 & 879.314 & 3-node bending /Y & 7 & 381.055 & 3- order radial collapse /X \\
\hline 8 & 885.232 & 3-node bending /X & 8 & 381.81 & 3- order radial collapse /Y \\
\hline 9 & 918.091 & Globe twist & 9 & 405.143 & 3-node bending /Y \\
\hline 10 & 927.198 & 3- order radial collapse /X & 10 & 405.151 & 3-node bending /X \\
\hline 11 & 928.593 & 3- order radial collapse /Y & 11 & 910.613 & Globe twist \\
\hline
\end{tabular}

From the results, with the reason of axial symmetry of geometric model, many bending vibration modes of the modal results are similar in the horizontal direction $(\mathrm{X})$ and vertical direction (Y). From the Tab.2, we can see that the stiffness of bending modes and radial collapse modes is decreased with the reason of water. Meanwhile, it can be found that the sequence of the coupling modes is different from air modal. Fig.4 and Fig.5 illustrate respectively the 2-node and 3-node horizontal bending vibration mode. Via the bending mode behavior of underwater robot, it is similar to beam.

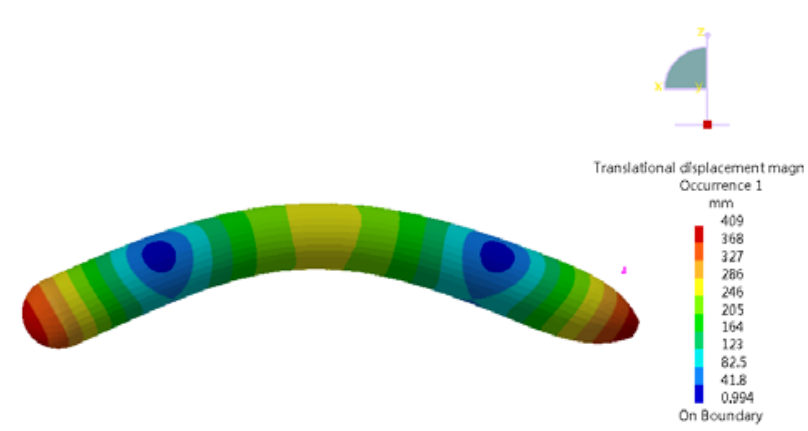

Figure 4. The 2-node bending mode 


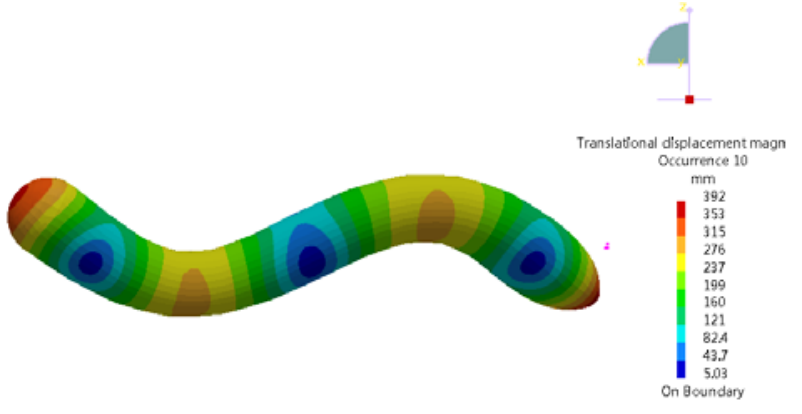

Figure 5. The 3-node bending mode

On the basis of modal analysis, harmonic response is calculated by the modal superposition method. Harmonic response load input conditions: the amplitude of excitation force $40 \mathrm{~N}$, frequency range $1 \mathrm{~Hz}-1100 \mathrm{~Hz}$, horizontal excitation direction, excitation position at the junction of motor shaft and shell stern section, analysis step $10 \mathrm{~Hz}$. Through calculation and analysis, it is concluded that the horizontal displacement response results of the underwater robot bow section (at front), midship section (at middle) and stern section (at end) as shown in Fig. 6.

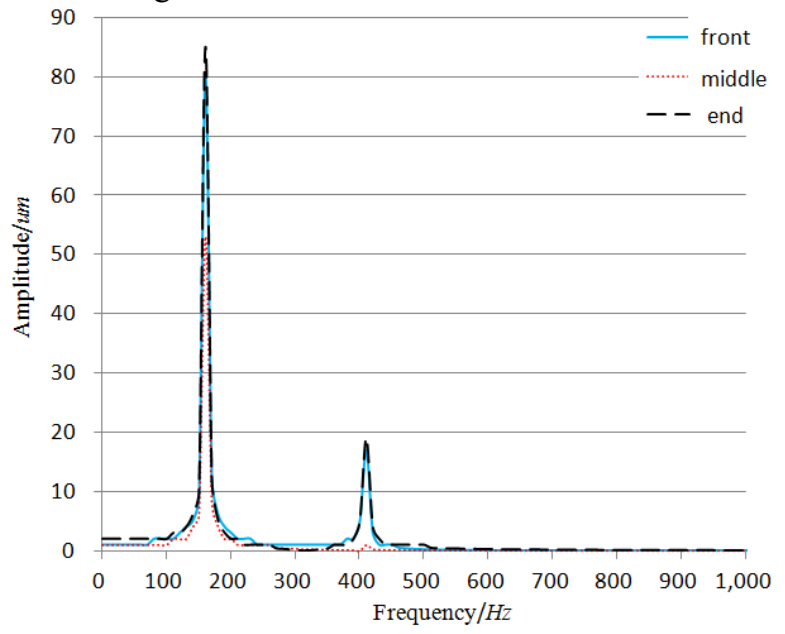

Figure 6. Horizontal displacement response underwater robot

The results indicate that: (1) The horizontal displacement response at $161 \mathrm{~Hz}$ is maximum, and the next is at $405 \mathrm{~Hz}$. (2) For $161 \mathrm{~Hz}$ and $405 \mathrm{~Hz}$ force, the horizontal displacement response at stern section is largest, and the next is at fore section. (3) The transverse displacement response is significantly greater than the longitudinal displacement response under the effect of transverse vibration force. (4) With the increase of frequency, due to the effect of damping, the response is reduced significantly, and represents low frequency characteristics.

The surface displacement nephograms under $161 \mathrm{~Hz}$ and $405 \mathrm{~Hz}$ exciting force are shown in Fig.7 and Fig.8. It is concluded that the simulation calculation is authentic via making a comparison between the robot displacement harmonic response results and fluid-structure coupling modal results.

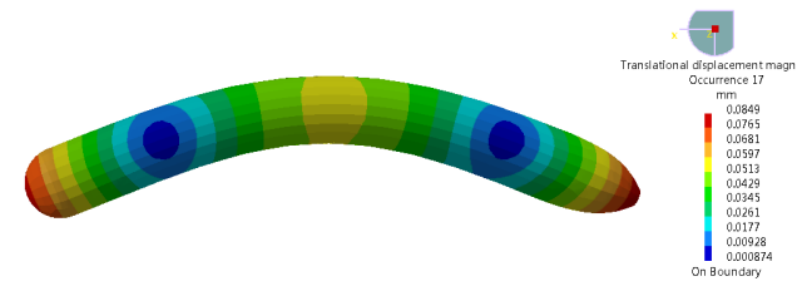

Figure 7. The displacement under $161 \mathrm{~Hz}$ force

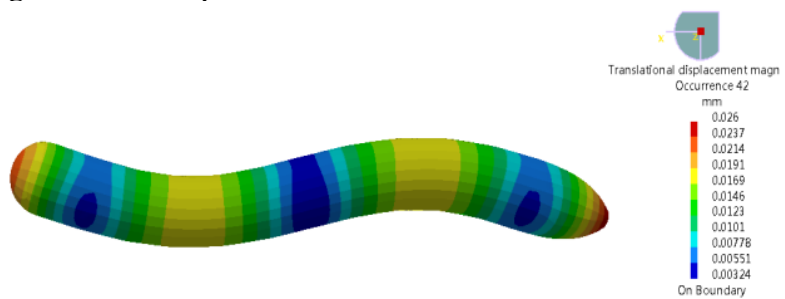

Figure 8. The displacement under $405 \mathrm{~Hz}$ force

\section{Simulation and characteristics analysis on sound radiation response for the small underwater robot}

Based on the boundary element theory method, the underwater robot infinite outer acoustic results are obtained by the input displacement load of the above the surface vibration response. In order to reflect the acoustic characteristics of the underwater robot, the plane sets of field test points are created on a vertical plane P1 and a horizontal plane P2 (See Fig.9). The reference sound pressure is $2 \times 10^{-5} \mathrm{~Pa}$. The sound pressure response results on plane $\mathrm{P} 1$ and $\mathrm{P} 2$ under $161 \mathrm{~Hz}$ and $405 \mathrm{~Hz}$ exciting force are shown in Fig.10-Fig.13, and the sound power level of field points is illustrated in Fig. 14.

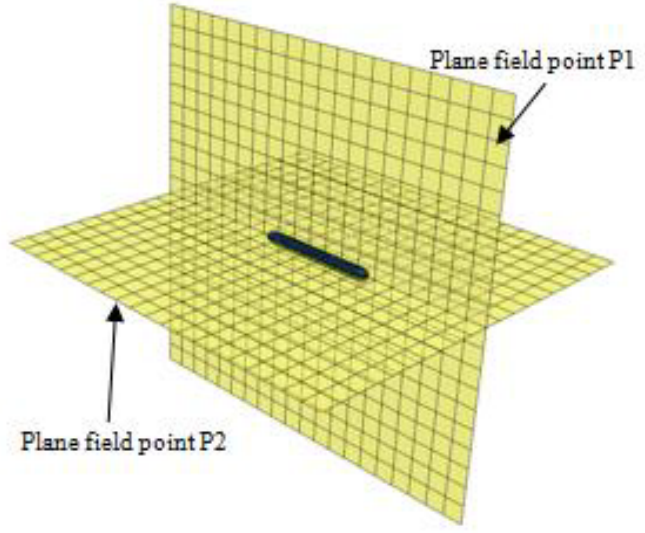

Figure 9. The field points on planes $\mathrm{P} 1$ and $\mathrm{P} 2$ 

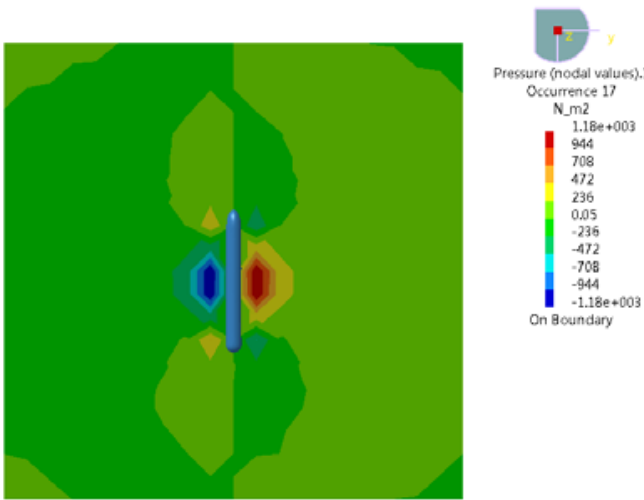

Figure 10. Pressure response on $\mathrm{P} 2$ at $161 \mathrm{~Hz}$
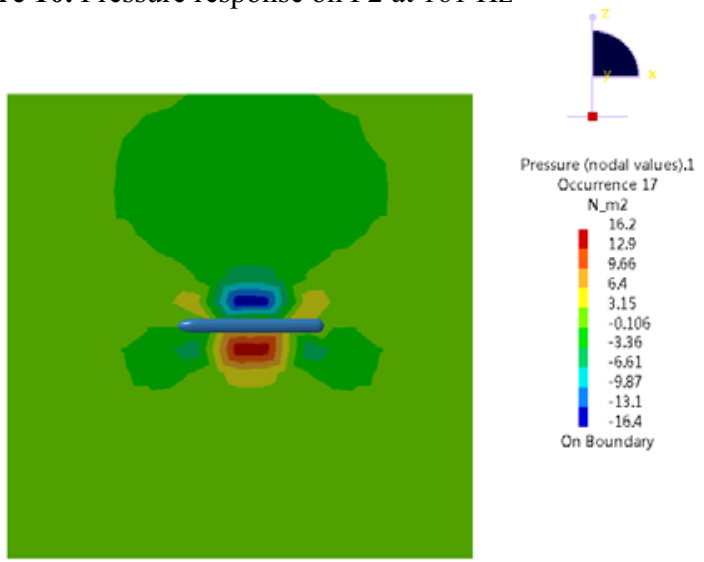

Figure 11. Pressure response on $\mathrm{P} 1$ at $161 \mathrm{~Hz}$
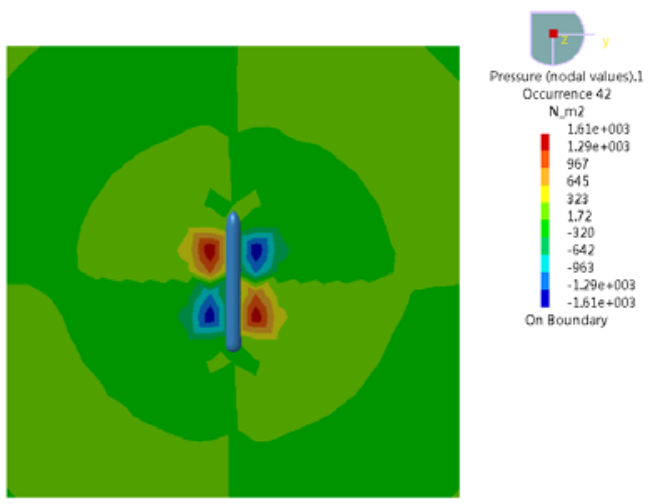

Figure 12. Pressure response on $\mathrm{P} 2$ at $405 \mathrm{~Hz}$
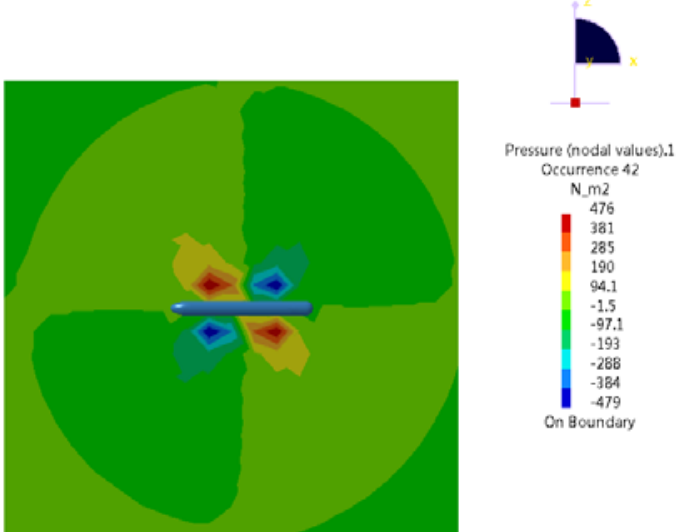

Figure 13. Pressure response on $\mathrm{P} 1$ at $405 \mathrm{~Hz}$

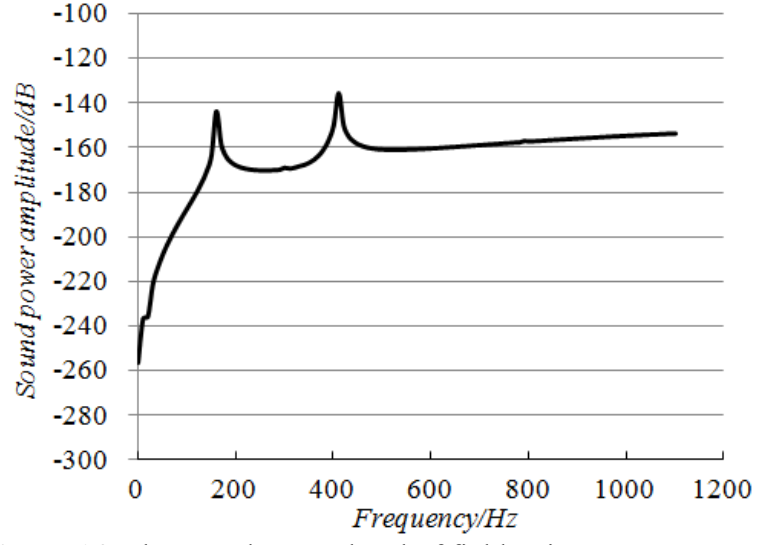

Figure 14. The sound power level of field points

The results indicate that: (1) the sound pressure at the middle side direction of the robot under $161 \mathrm{~Hz}$ transverse exciting force is largest. (2) Under $405 \mathrm{~Hz}$ transverse exciting force, the sound pressure is large at the peak positions of 3 -node vibration mode. (3)The sound power level value is largest at frequency $405 \mathrm{~Hz}$; (4) The 3-node vibration mode at $405 \mathrm{~Hz}$ has larger amount of contribution to acoustic radiation than the 2-node vibration mode at $161 \mathrm{~Hz}$.

\section{Conclusions}

By means of combining FEM and BEM, the structure of the underwater robot fluid-structure coupling modal frequencies and vibration modes are obtained. It is found that the sequence and stiffness of modes in water are different from the modes in air. The 2-node bending vibration displacement response is greater than the 3node vibration displacement response, but the contribution to the sound radiation of the 3-node bending is high. Thus, in order to increase the stealth performance of underwater robot, the 2-node and 3-node vibration modes must to be controlled. What's more, the researched method and results in the paper are important to avoid the coupling resonance frequencies of the robot shell for the dynamic design, the selection of navigational conditions and key equipment, such as propulsion motor, rudder motor and propeller.

\section{References}

1. S. Merz, R. Kinns,N.Kessissoglou, Journal of Sound and Vibration, 325, 266-286(2009).

2. S. Merz, N. Kessissoglou, R.Kinns, Proceedings of the 14th International Congress on Sound and Vibration (2007).

3. J. Pan, N. Farag, T. Lin, R. Juniper, Proceedings of Innovation in Acoustics and Vibration Annual Conference of the Australian Acoustical Society (2002).

4. O. Rath Spivack, R. Kinns, N. Peake, Journal of Marine Science Technology, 9, 109-116(2004).

5. Wu G X, R Eatock Taylor, Ocean Engineering,30, 387-400(2003). 
6. Young D L, Liu Y H, Eldho T I, Engineering Analysis with Boundary Elements, 24, 307-316 (2000).

7. Chen Z S, Hofstetter G, Mang G A, Methods Appl. Mech. Engrg. , 152, 147-155(1998). 